Sustainability 2013, 5, 1-x manuscripts; doi:10.3390/su50x000x

Article

\title{
The Sustainability of Community-Based Adaptation in the Choke Mountain Watersheds, Blue Nile Highlands, Ethiopia
}

\author{
Belay Simane \\ Center for Environment and Development, College of Development Studies, Addis Ababa \\ University, Addis Ababa, Ethiopia. E-Mail: simaneb@yahoo.com; Tel.: +251-911-223-044.
}

Received: 14 August 2013 / Accepted: 27 September 2013 / Published: 01 November 2013

\begin{abstract}
Adaptation to climate change is becoming an increasingly important part of the development agenda in Ethiopia. Twenty-one Community Based Organizations (CBOs) were established in the Choke Mountain Watersheds of the Blue Nile Highlands to assess the sustainability community-based adaptation. They organized themselves voluntarily, established their own bylaws, and opened bank accounts to manage various transactions. Existing field-based extension approaches and methods of watershed planning were implemented with the active participation of the local level administration. The adaptation options focused on options that are proven environmentally and economically successful elsewhere, but are not widely known or practiced in the Choke Mountain watersheds, i.e. "no regret" options. Conservation of the natural resource base was taken as an entry point for planning adaptive actions. The sustainability of individual CBOs was assessed using Analytical Hierarchy Process based Multi-Criteria Analysis applied to five sustainability dimensions. Total sustainability was calculated as the average sustainability score $(0 \%$ to $100 \%$ ) across all dimensions. For the $21 \mathrm{CBOs,}$ total sustainability values ranged from $39 \%$ to $66 \%$, with a median of $47 \%$. No sustained CBO that obtained a total sustainability score $\geq 70 \%$, which would be an indicator of strong sustainability. Six CBOs (28.6\%) achieved a 50\% score or greater in an aggregated form from all dimensions, and were judged to be sustainable but at risk. The rest $71.4 \%$ (15 CBOs) failed to obtain a $50 \%$ score in an aggregated form or in any of the factors, and are judged to be unsustainable in all dimensions. Repeatedly occurring critical barriers to sustainability are inadequacies in community participation, training of local community members, local government commitment, farmers' capacity, extended bureaucracy. Based on this experience, we recommend that markets are a more appropriate entry and exit point for resilience building efforts by establishment and implementation of community-based innovation platforms, devoted to achieving a climate resilient and green economy through dissemination and uptake of proven technologies and practices.
\end{abstract}

Key words: Adaptation, Analytic hierarchy process; Community Based Organizations, Ethiopia, Multi-criteria analysis; Sustainability; 


\section{Introduction}

A community-based approach helps to alleviate prevent environmental and social problems instead of having external actors step in and assume these responsibilities on behalf of the communities. A major challenge to integrate $\mathrm{CC}$ adaptation and development at local level stems from the lack of capacity and sustainable institutions to coordinate and lead local level efforts. Another challenge in the current adaptation work is to understand and demonstrate how adaptation works and what the implications of adaptation for resilience are at community level. Therefore, adaptation to climate change (CC) has become a fundamental issue in the development agenda of Ethiopia [1].

The Climate Resilient Green Economy (CRGE) strategy document of Ethiopia also emphasizes that projects run by community-based organizations can mobilize participants to take on more sustainable practices [2, 3]. The country's a five-year Growth and Transformation Plan (GTP), which aims to foster high and broad-based growth, also highlights the vital role of environmental conservation in the sustainable development of the country [4]. Realizing this ambition requires sustainable community-based institutions that are implementing conservation and rehabilitation of environmental resources as well as implementing green technologies as an essential part of the CRGE actions.

Community-based adaptation (CBA) is a process based on priorities of communities' needs, knowledge, and capacities, that empower people to plan and adapt to the impacts of CC [5]. The goal of CBA projects is to increase the resilience of communities by enhancing their capacity to cope with CC impacts. The rationale for this approach is that local context requires sustainable local knowledge. While CC mitigation is a global challenge to which rural, developing communities can make little contribution,, there is much that can be done at the local level to reduce the impacts of CC. Through an understanding of how people cope with and adapt to climate variability consistent with predicted CC effects, meaningful measures can be taken to reduce vulnerability to $\mathrm{CC}$ and its broader social and economic consequences.

Effective CBA depends on the establishment of sustainable adaptation-oriented Community Based Organizations (CBOs). The "sustainability" of a CBO, in turn, depends on empowerment of organizations, such that members are capable of planning and implementing their development initiatives independently [6]. The fundamental requirement for a CBO to be sustainable depends up on the power that lies within it [7]. Community driven developments are part of a broader paradigm shift responding to critiques of top-down approaches that have dominated development over the years.

There are growing opportunities for local level development projects targeted to adapt and manage CC risks and bring sustainable development, supported by national and international investments. Community-based management (CBM) incorporates both a topdown and bottom-up approach that involves local community, government, and non- 
governmental organizations. It has also been applied to designate approaches where local communities play a central but not exclusive role in rural sustainable development process management. Therefore, the establishment and maintenance of good governance is very critical to ensure the success of rural sustainable development $[8,9]$.

A community-based approach is a way of working in partnership with persons of concern during all stages of project cycles. It recognizes the resilience, capacities, skills and resources of local communities, builds on these to deliver protection and solutions, and supports the community's goals. It demands first on proper understanding and consideration for local priorities, political and cultural contexts, and livelihoods. The sustainability and effectiveness of the approach heavily depends on the meaningful participation of all community members, and not just a cadre of elites. The elites' role is to facilitate discussions and analysis with persons of concern so that each participant can identify their own priorities and preferred outcomes.

CBOs in the Choke Mountain Watersheds were established to improve food security and alleviate poverty in local communities while maintaining the sustainability of ecosystems. This project was particularly concerned with the role of CBOs in conservation and integrated management of Choke Watersheds biodiversity. Specific objectives include:

- conserve biodiversity at farm level;

- reduce the high rate of deforestation at the watershed level;

- improve crop productivity;

- reduce the extent of soil erosion in the watershed;

- improve livestock production; and

- build and strengthen the overall capacity of the Cooperative members.

For the project area there are no reliable, downscaled data on potential impacts of CC, so the project focused on options that have proven to provide environmental and economic benefits under current climate conditions-i.e. "no regrets" adaptation options - but that are not widely known or practiced in the Choke Mountain watersheds [12]. This strategy serves the purpose of establishing field demonstrations to raise awareness, and establishing a pool of adaptation technologies with known benefits, and costs are by farmers and development agents can be implemented immediately. The project facilitated meetings that included local authorities, government partners and the receiving population to overcome differences in attitudes and supported capacity building at different levels.

The cooperatives and experts, to address food security issues and rehabilitate ecosystems of the Choke Mountains Watersheds, adopted the Comprehensive and Integrated Livelihood with Watershed Management Approach [11]. All interventions were designed to give due emphasis to conservation of Farmers' Varieties, natural resources, improvement of the livelihoods of the community, community participation and gender equity.

Core activities pursued through CBOs and their supporting institutions include: 
- Building and strengthening the capacity of the CBOs: In order to build and strengthen the capacity of $\mathrm{CBO}$, major activities such as training of, local community and administrators, the community planning team, and development agents (DAs), developing local level environmental action plan, holding educational visits and annual workshop involving stakeholders are crucial . Projects with training of experts, development agents, and community members components are more likely to be sustained than those without: those trained can continue to provide benefits, train others, and form a constituency in support of the program $[10,11]$.

- Conserving biodiversity: Activities that contribute to the conservation of biodiversity at the farm level include conserving the locally important farmers' varieties (FV) through in situ conservation ; bee keeping ; and establishing protected area by developing a management plan for protected area to conserve the biodiversity resources with provisions of benefit sharing with the local communities.

- Reducing deforestation: Activities to reduce demand for wood, such as trainings in Gonzie stove production (females who are landless in the watershed selected and trained by providing workshop shade, Gonzie stove casting mold, different hand tools and other materials), and direct actions to counter deforestation, such as establishing protected forest and community woodlots.

- Improving crop productivity: The majority of Choke Mountain people is dependent on marginal, sloping agricultural lands and communally used forests and pastures for their livelihoods. Watershed management provides an integrative framework for sustainable livelihoods and natural resource management. As the demand for land increases with growing population pressure, and as soil nutrients are depleted through intensified agriculture, there is continuing expansion on to new slopes and unsustainable use of old ones. Sloping land agriculture is susceptible to high rates of soil erosion, loss of soil fertility, and poor retention of water. In order to improve crop productivity, CBOs focused on nutrient enhancement through composting and soil conserving cultivation such as growing highland fruits.

- Improving soil and water conservation practices: To reduce the extent of soil erosion at the watershed level, major CBO activities include soil and water conservation practices such as bund construction, hillside terrace construction, and conservation tillage. Capacity for these activities is supported through procurement of the necessary equipment and tools, training, and establishment of school environment clubs that raised awareness, took prepared tree nurseries, and planted nursery seedlings on school grounds. 
- Improving livestock production: Improvements in livestock included improved management of communal pasture (practicing shifting grazing and cut and carry system), enriching pasture, producing hay, and practicing tethering or stall feeding.

This paper provides a summary of the working approach developed and tested to promote community-based adaptation in the rural areas of Ethiopia. It brings to light the lessons learned from the implementation process of $21 \mathrm{CBOs}$ that were organized in the Choke Mountain watersheds over the last 5 years (2008-2012). Based on these lessons, we explore ways in which CBOs could be made more sustainable and contribute to national efforts to build resilience and the green economy in the context of $\mathrm{CC}$. We emphasize that the adaptation process also benefits the conservation and rehabilitation of natural resources, which is the primary basis of livelihoods in farming communities

\section{Methodology}

\section{Institutional groundwork}

The interventions focused on vulnerability reduction and adaptation by establishing community-based projects. The research assumed that success in managing natural resources and bringing sustainable development are mainly the functions of capacities created to enable relevant stakeholders effectively plan and implement projects addressing their needs at different levels. Realization of these demands genuine participation. It also assumed that local communities have rich indigenous knowledge that is relevant to their localities.

In 2007, Addis Ababa University College of Development Studies and the Ethiopian Society for Appropriate Technology (ESAT) in collaboration with the East Gojam Zone of Amhara Regional State Environmental Protection Authority initiated community-based adaptation projects to improve the adaptive capacities of rural populations and their resilience to drought and other CC impacts. Twenty-one local CBOs were established with the facilitation of the woreda administration, agriculture office, and cooperatives office to achieve natural resource management [10]. In establishing these CBOs and implementation of adaptation options prioritized by the community, existing field-based extension approaches and methods were used with active participation of woreda level working groups chaired by the respective woreda administrators.

Field orientation meetings were organized before the planning stage with local administration, experts and farmers. Frequent field visits of the researchers and development workers from the Woreda and Zonal Agriculture office, as well as on-the-spot technical training sessions helped the implementation cycle of various options. Farmer-to-farmer learning was motivated through several extension approaches including orientation meetings, field days and exchange visits. 
In all 21 communities, local agricultural and environment experts and development agents (Das) were trained to take the lead in initiating the CBO process. Skill training by woreda as well as zonal technical taskforce members have imparted important opportunities such as Soil and Water Conservation (SWC), bee keeping, production and use of fuel saving stoves (both traditional as well as modern), and training on organizational and financial management topics to CBOs. In addition, experience-sharing activities among CBOs were very instrumental to social sustainability. Community wide discussion, dialogue, and reaching into a consensus were the cornerstones of sustainability. While the ultimate goal of this step was to raise public awareness about the community-based project development to be initiated, establishing local level working group, and clearly articulating the community vision were the intended outputs. A core group of committed individuals who are interested in bringing the community together to address environmental issues initiated it.

\section{Operational structure of the CBOs}

Management leaders, organized into three teams, which were elected by the General Assembly, led operations of the CBOs. After establishment of Community Natural Resources Conservation and Tourism Cooperative (CNRCTC), the CBO leaders further extended their operational structure into different teams. Each development team has three leaders and twenty-seven members organized in locational convenience. Accordingly, all activities of the CBO including the decision passed in the General Assembly and management team are organized and implemented through these teams in collaboration with the CBO leaders.

Existing field-based extension approaches and methods of watershed planning were used with the active participation of local administration. The local technical team following participatory watershed management planning methods organized an initial planning [11]. Finally, the list of viable adaptation options was presented to local farmer groups, who selected suitable adaptation options for their localities following a 5-step environmental management planning process.

Project implementation is the responsibility of the CBO with support of different partners. At local level, the major partners involved are community members, local administration and sector experts, such as woreda and zone agriculture and rural development experts. The woreda agriculture and rural development offices have played a vital role in mobilizing the community, conducting trainings, monitoring project activities while the zone agriculture, and rural development office has been responsible for technical and administrative backstopping. The woreda Cooperatives Promotion Office was responsible for improving governance and administrative aspects of the cooperatives. All stakeholders of the project, including Addis Ababa University, Environmental Protection Authority, and ESAT have provided technical assistance to the cooperative throughout the implementation period.

\section{Methodology}


The methodology used in this study involved a combination of descriptive and quantitative research and included the use of descriptive analysis as data processing methods. A cross-sectional research was used to assess the sustainability of the CBOs activities, participation of its members and the effectiveness of the bylaws. Data were collected from both primary and secondary sources. Primary data was collected using a multitude of data collection techniques, which includes structured questionnaire, key informant interviews, and focus group discussions. Pertinent secondary sources of data were also collected from different sources.

Participation of the members was conducted on a sample of 124 households found in the micro-watershed, which in this case are the major unit of analysis. Furthermore, key informant interview was held with 17 knowledgeable informants who among others include local communities, experts, focal persons of external support and others. Focus group discussions were also held with three groups, namely, men group, women group and watershed team leaders group.

We adopted the Analytical Hierarchy Process (AHP) based Multi-Criteria Analysis (MCA) method which is a structured approach to determine the sustainability of CBOs in CC adaptation process $[13,14]$. It brings the effectiveness of all the components of the planned activities together in a hierarchical decomposition of the overall goal. A hierarchical structure of these factors is formed by grouping them into different levels. The overall goal of establishing CBOs lies at the top and the different components and their indicators to be evaluated are placed at the lowest level of the hierarchy. The goal of this framework is to assess the sustainability of the CBO-based adaptation actions. On the next lower level are the dimensions major criteria, which are used to evaluate the sustainability of the CBOs. The variable that determine the sustainability criteria are presented in the third column. Variables are measured, judged, or rated for each $\mathrm{CBO}$, while monitoring sustainability in the field compared with the planned activities.

The hierarchal structure used to evaluate the sustainability of the $21 \mathrm{CBO}$ and the potential contribution of the factors following the MCA approach is presented in Table 1 . The comparative weights given to dimensions and factors in MCA were determined through participatory methods involving sector professionals and field workers. Further, each factor is rated considering its significance to overall sustainability.

Five sustainability dimensions (social, institutional, technical, financial, and environmental) are identified as the highest level of sustainability indicators and rated according to their contribution (Table 1). For each dimension second-order, indicators or factors are identified based on the project proposal. Each of these indicators at the lowest level of the hierarchy are rated for acceptance by each individual CBO on a five point scale of Very low (<30\%), Low (30-50\%) Moderate (50-70\%) High (70-90\%), Very High ( $>90 \%$ ). Based on the weights of the factors and sub-factors obtained from pairwise 
comparison from AHP are multiplied with the respective ratings for sub-factors, total score is obtained for the particular CBO that indicates its sustainability. CBOs are then classified into three categories according to their sustainability score i) Sustained $C B O$ : The project obtains a $70 \%$ score (or more) in all sustainability dimensions, in aggregated form and in each core factor, ii) Sustained but at risk CBO: The project obtains a 50\% score (or more) in an aggregated form and in each core factor and iii) Not sustained $C B O$ : The project fails to obtain a $50 \%$ score in an aggregated form or in any of the core factors.

Table 1. The hierarchal structure used to evaluate the sustainability CBOs and the comparative weights given to dimensions and indicators/factors

\begin{tabular}{|c|c|c|c|}
\hline $\begin{array}{l}\text { Goal of } \\
\text { establishing CBOs }\end{array}$ & Dimensions & Indicators/factors & Rating factors \\
\hline \multirow{5}{*}{$\begin{array}{l}\text { Sustainability of the } \\
\text { CBOs: Biodiversity } \\
\text { Conservation and } \\
\text { Sustainable } \\
\text { Watershed } \\
\text { Management }\end{array}$} & $\begin{array}{l}\text { Social } \\
\text { sustainability } \\
(0.1)\end{array}$ & $\begin{array}{l}\text { - } \begin{array}{l}\text { Training of local Communities and } \\
\text { administrator }\end{array} \\
\text { - Information and Knowledge } \\
\text { management } \\
\text { - } \begin{array}{l}\text { Establishing school environmental } \\
\text { club }\end{array} \\
\text { - } \begin{array}{l}\text { Developing Local Level } \\
\text { Environmental Action Plans }\end{array}\end{array}$ & $\begin{array}{l}0.03 \\
0.03 \\
0.03\end{array}$ \\
\hline & $\begin{array}{l}\text { Institutional } \\
\text { sustainability } \\
(0.2)\end{array}$ & $\begin{array}{ll}\text { - } & \text { Training for: Planning team: DAs' } \\
& \text { Expertise: Trainer } \\
\text { - } & \text { Supervision } \\
\text { - } & \text { Annual Workshop }\end{array}$ & $\begin{array}{l}0.067 \\
0.067 \\
0.067\end{array}$ \\
\hline & $\begin{array}{l}\text { Technical } \\
\text { sustainability } \\
(0.5)\end{array}$ & $\begin{array}{l}\text { - } \text { Improved SWC Practices } \\
\text { - } \quad \text { Conservation of locally important } \\
\text { - } \text { farmers'varieties } \\
\text { - } \quad \text { Composting } \\
\text { - } \quad \text { Production of Mirt Stove } \\
\text { - } \quad \text { Communal Pasture management } \\
\text { - } \text { Bee keeping } \\
\text { - Forest Establishments }\end{array}$ & $\begin{array}{l}0.056 \\
0.056 \\
0.056 \\
0.056 \\
0.056 \\
0.056 \\
0.056\end{array}$ \\
\hline & $\begin{array}{l}\text { Financial } \\
\text { sustainability } \\
(0.1)\end{array}$ & $\begin{array}{ll}\text { - } & \text { Financial management } \\
\text { - } & \text { Audit } \\
\text { - } & \text { Improved household income } \\
\text { - } & \text { Diversified Income sources } \\
\text { - } & \text { Contributions }\end{array}$ & $\begin{array}{l}0.02 \\
0.02 \\
0.02 \\
0.02\end{array}$ \\
\hline & $\begin{array}{l}\text { Environmental } \\
\text { sustainability } \\
(0.1)\end{array}$ & $\begin{array}{ll} & \text { Formulation of bylaws } \\
- & \text { Delineation of area Closure } \\
- & \text { Establishment of management plan } \\
\text { - } & \text { Introduce enrich biodiversity } \\
\text { - } & \text { Spring development } \\
& \text { Construction of water trough }\end{array}$ & $\begin{array}{l}0.017 \\
0.017 \\
0.017 \\
0.017 \\
0.017\end{array}$ \\
\hline
\end{tabular}




\section{Results and Discussions}

\section{CBO's profile}

The 21 CBOs were organized and established during 2007 and 2008 as natural resource conservation and tourism cooperative (CNRCTC) and got legal entity from the respective woreda cooperative offices (Table 2). This was a requirement to open official bank account and receive financial support from GEF Small-grants programme. The objective of these CBOs were conserving and rehabilitating the natural resource base following a watershed approach.

These CBOs envisaged empowering the local people of creating lasting community wide progress in their livelihood, bio-diversity conservation, abating soil degradation and related social services. They have developed their own bylaw/constitution stipulating, among others, the vision, mission and objectives, membership criteria, terms of office for the executive committee members, arbitration procedure, financial management, organizational structure and staffing, duties and responsibilities of different bodies, penalty for illegal act of members and leaders and procedures in case of liquidation.

The CBOs got the financial support mainly from GEF Small Grants Programme (SGP). Some resources are also mobilized from its members in the form of registration fee, sales of share and different inputs, labour and materials. While the total beneficiaries are 10267 households (8907 male and 1360 female), the total external financial support from GEF Small Grant programme is ETB 5.4 million (492393 USD). Membership of these CBOs has been steadily growing since establishment as people come to realize the benefit of organizing in association/cooperative to get better benefit collectively rather than individually. The Woreda administrations have also contributed considerable amount in the form of technical assistant, knowledge transfer and improved inputs. 
Table 2. Choke mountain Natural Resources Development and Tourism Marketing Cooperative profiles

\begin{tabular}{|c|c|c|c|c|c|c|c|c|}
\hline \multirow[t]{2}{*}{ No } & \multirow[t]{2}{*}{ Woreda } & \multirow[t]{2}{*}{$\mathrm{CBO}$} & \multicolumn{2}{|c|}{ Financial Support } & \multicolumn{3}{|c|}{$\begin{array}{l}\text { Beneficiaries } \\
\text { No of Households }\end{array}$} & \multirow[t]{2}{*}{$\begin{array}{l}\text { Watershed } \\
\text { Size in ha }\end{array}$} \\
\hline & & & ETB & USD & Male & Female & Total & \\
\hline \multirow[t]{9}{*}{1} & \multirow[t]{9}{*}{ Sinan } & Ababule & 223000 & 19983 & 1228 & 182 & 1410 & 500 \\
\hline & & Abajime & 287710 & 30303 & 267 & 49 & 316 & 467 \\
\hline & & Abo & 250875 & 22559 & 2286 & 442 & 2728 & 1068 \\
\hline & & Chemoga & 268415.62 & 25172 & 280 & 50 & 330 & 620 \\
\hline & & Godeb & 250875 & 24221 & 319 & 67 & 386 & 620 \\
\hline & & Temcha & 261530 & 25063 & 320 & 50 & 370 & 934 \\
\hline & & Work Awtuley & 251946 & 20156 & 270 & 50 & 320 & 525 \\
\hline & & Zumander & 268412 & 21473 & 316 & 49 & 365 & 745 \\
\hline & & Sub Total & 2062763.6 & 188930 & 5286 & 939 & 6225 & 5479 \\
\hline \multirow[t]{9}{*}{2} & \multirow[t]{9}{*}{$\begin{array}{l}\text { Dibay } \\
\text { Tilatgin }\end{array}$} & Boreborit & 202561 & 18167 & 224 & 28 & 252 & 237 \\
\hline & & Tsion & 244835 & 21958 & 220 & 7 & 227 & 385 \\
\hline & & Washa & 257630 & 26142 & 297 & 21 & 218 & 467 \\
\hline & & Woifen Adkim & 243280 & 26695 & 401 & 46 & 447 & 500 \\
\hline & & Yegomera & 256229 & 22980 & 146 & 9 & 155 & 625 \\
\hline & & Jibara Meda & 238030 & 26168 & 298 & 17 & 315 & 467 \\
\hline & & Ambaber & 257756 & 20620 & 500 & 90 & 590 & 900 \\
\hline & & Dedek & 251371 & 20109 & 148 & 25 & 173 & 245 \\
\hline & & Sub Total & 1951692 & 182839 & 2234 & 243 & 2377 & 3826 \\
\hline \multirow[t]{7}{*}{3} & \multirow[t]{6}{*}{ Bibugn } & $\begin{array}{l}\text { Adagn } \\
\text { Medehanealem }\end{array}$ & 273381.44 & 27721 & 320 & 50 & 370 & 650 \\
\hline & & $\begin{array}{l}\text { Bahiru Arusi } \\
\text { Dong }\end{array}$ & 216461 & 19414 & 67 & 29 & 196 & 292 \\
\hline & & Gedeb Giorgis & 348243 & 31233 & 373 & 45 & 418 & 971 \\
\hline & & Meleya & 245612 & 22028 & 259 & 13 & 272 & 330 \\
\hline & & Adisalem & 252846 & 20228 & 368 & 41 & 409 & 612 \\
\hline & & Sub Total & 1336543.4 & 120624 & 1387 & 178 & 1665 & 2855 \\
\hline & & Total & 5350999.1 & 492393 & 8907 & 1360 & 10267 & 12160 \\
\hline
\end{tabular}

Source: Project Proposals of CBOs

\section{The sustainability of CBOs}

All CBOs are founded based on a rights-based approach, which is founded on the principles of participation and empowering individuals and communities to promote change and enable them to exercise their rights and comply with their duties. The sustainability of CBOs at the planning phase and its organizational structure helps to ensure that the community is targeting the serious problems, i.e. those actions where environmental improvements can be readily achieved. As the primary institution responsible for implementing the planned activities, it is critical that CBOs takes full "ownership" of the activity plan for implementation. The community participation on implementation of the intended activities was found gaining a positive momentum after some delays in most activities due to reasons associated with awareness, attitudinal problems of some farmers and problems associated during the planning phase and the organizational structures of the CBOs. 
Table 2 Descriptive Statistics of the Sustainability Indicators of the Community based Organizations

\begin{tabular}{|c|c|c|c|c|c|c|}
\hline \multirow[b]{2}{*}{ CBOs } & \multicolumn{5}{|c|}{ Dimensions of Sustainability } & \multirow{2}{*}{$\begin{array}{c}\text { Sustainability } \\
\text { of CBOs }\end{array}$} \\
\hline & Social & Institutional & Technical & Financial & Environmental & \\
\hline Gedebgiorgis & 0.07 & 0.06 & 0.37 & 0.1 & 0.06 & $0.66 * *$ \\
\hline Melya & 0.04 & 0.04 & 0.21 & 0.08 & 0.03 & $0.4^{*}$ \\
\hline Addis & 0.04 & 0.04 & 0.21 & 0.08 & 0.06 & 0.43* \\
\hline Bahiru & 0.05 & 0.04 & 0.26 & 0.08 & 0.03 & $0.46 *$ \\
\hline Adagn & 0.07 & 0.05 & 0.37 & 0.08 & 0.07 & $0.59 * *$ \\
\hline Worke & 0.04 & 0.06 & 0.22 & 0.08 & 0.03 & $0.43 *$ \\
\hline Zumander & 0.04 & 0.06 & 0.26 & 0.07 & 0.04 & $0.47 *$ \\
\hline Abagimie & 0.05 & 0.05 & 0.26 & 0.07 & 0.06 & 0.49* \\
\hline Temcha & 0.05 & 0.05 & 0.26 & 0.07 & 0.07 & $0.5^{* *}$ \\
\hline Ababilie & 0.04 & 0.05 & 0.26 & 0.08 & 0.05 & 0.48* \\
\hline Abo & 0.05 & 0.05 & 0.28 & 0.08 & 0.04 & $0.5^{* *}$ \\
\hline Chemoga & 0.05 & 0.05 & 0.27 & 0.07 & 0.07 & $0.51 * *$ \\
\hline Godeb & 0.05 & 0.05 & 0.29 & 0.07 & 0.04 & $0.5^{* *}$ \\
\hline Washa & 0.06 & 0.04 & 0.31 & 0.01 & 0.06 & $0.48 *$ \\
\hline Gibara & 0.06 & 0.04 & 0.27 & 0.01 & 0.03 & $0.41 *$ \\
\hline Wyifen & 0.06 & 0.04 & 0.29 & 0.01 & 0.06 & $0.46 *$ \\
\hline Yegomira & 0.05 & 0.04 & 0.27 & 0.01 & 0.03 & $0.4^{*}$ \\
\hline Boreborit & 0.05 & 0.04 & 0.26 & 0.01 & 0.03 & 0.39* \\
\hline Tsion & 0.05 & 0.04 & 0.27 & 0.01 & 0.03 & $0.4^{*}$ \\
\hline Ambaber & 0.05 & 0.04 & 0.27 & 0.01 & 0.03 & $0.4^{*}$ \\
\hline Dedeke & 0.04 & 0.03 & 0.29 & 0.01 & 0.03 & $0.4^{*}$ \\
\hline Rating & 0.1 & 0.2 & 0.5 & 0.1 & 0.1 & 1.0 \\
\hline Minimum & .04 & .03 & .21 & .01 & .03 & 0.39 \\
\hline Maximum & .07 & .06 & .37 & .10 & .07 & 0.66 \\
\hline Mean & .0505 & .0460 & .2740 & .0540 & .0460 & $0.4680 *$ \\
\hline Std. Deviation & .00945 & .00821 & .04160 & .03378 & .01603 & 0.06818 \\
\hline
\end{tabular}

*** Sustained CBOs, ** Sustained but at risk, * Not sustained CBO

The sustainability of Individual CBOs that are assessed on aggregate rating of the social, institutional, technical, and financial and environment dimensions by summing the lowest level indicators of the hierarchy (Table 3). The descriptive statistics of the variable used in assessing Sustainability of Community based Organizations are presented in Annex 1. The five sustainability dimensions namely social, institutional, technical, financial and environmental are rated as $0.1,0.2,0.5,0.1$ and 0.1 respectively according to their contribution in achieving the aims of the CBOs. Social sustainability indicators ranged from 0.04 (Meleya, Addis, Worke and Zumander) to 0.07 (Gedebgiorgis) with a median value of 0.0505 . Institutional sustainability indicators ranged from 0.03 to 0.06 with a median value of 0.046 , which is much lower than the expected average value. Technical sustainability 
indicators contribute halve of the overall sustainability (50\%) and ranges from 0.21 to 0.37 with a median value of 0.274 which is far better than all the other indicators. While financial sustainability ranges from 0.01 to 0.1 , environmental sustainability indicator ranged from 0.03 to 0.07 with median values of 0.054 and 0.046 respectively.

The aggregate value of sustainability ranges from 0.39 to 0.66 with a median of 0.4680 , which is below the average value. There is no sustained CBO that obtains a $70 \%$ score (or more) in all sustainability dimensions and in aggregated form. 6 CBOs $(28.6 \%)$ sustained but at risk CBO getting a 50\% score (or more) in an aggregated form from all dimensions (Table 4). The rest $71.4 \%$ (14 CBOs) fail to obtain a 50\% score in an aggregated form or in any of the factors and are not sustainable in all the dimensions.

\section{Table 4. Sustainability results of CBOs}

\begin{tabular}{|l|c|c|c|c|}
\hline \multirow{2}{*}{$\begin{array}{l}\text { Dimension of } \\
\text { Sustainability }\end{array}$} & \multicolumn{3}{|c|}{ Number of CBOs in percentage } & \multirow{2}{*}{$\begin{array}{l}\text { Aggregate } \\
\text { value }\end{array}$} \\
\cline { 2 - 5 } & Sustained (\%) & Sustained-risk (\%) & Not sustained (\%) & \\
\hline Social & $\mathbf{0}$ & $\mathbf{7 0}(\mathbf{1 4})$ & $\mathbf{3 0}(\mathbf{6})$ & \\
\hline Institutional & $\mathbf{0}$ & $\mathbf{0}$ & $\mathbf{3 0}(\mathbf{3})$ & \\
\hline Technical & $\mathbf{1 5}(\mathbf{3})$ & $\mathbf{6 0}(\mathbf{1 5})$ & $\mathbf{3 5}(\mathbf{7})$ & \\
\hline Financial & $\mathbf{0}$ & $\mathbf{6 5}(\mathbf{1 3})$ & $\mathbf{6 0}(\mathbf{1 2})$ & \\
\hline Environmental & $\mathbf{0}$ & $\mathbf{4 0}(\mathbf{8})$ & $\mathbf{( 1 4 )}$ & \\
\hline Aggregate value & $\mathbf{0}$ & $\mathbf{3 0}(\mathbf{6})$ & & \\
\hline
\end{tabular}

\section{Barrier analysis to the implementation community-based adaptation}

Another major outcome of the study was a multiple criteria participatory framework for sustainability monitoring including identification of strong/weak areas, which are contributing to maintaining/lowering the sustainability status. A stakeholders' workshop (Debre Markos, Ethiopia, 10-11 June 2011) [10] identified the criteria-wise contribution to the sustainability of CBOs by key dimensions, which are considered to be vital information for recommendations to increase the likelihood of sustainability of the existing CBOs. The critical barriers across the studied CBOs performance that are areas for improvement in the future are presented in Table 5 in top down order.

These barriers are due to the lack of understanding of the adaptation process, information, and impact assessments, political mainly inter-departmental conflicts, issues of 'territoriality', lack of guiding principles and understanding at woreda and kebele level; and cultural such as thoughts of not overstepping existing activities and traditions and lack of insight to working at landscape level as a community problems 
Table 5. Key dimensions affecting sustainability

\begin{tabular}{|c|c|c|c|}
\hline \multirow{2}{*}{$\begin{array}{l}\text { Dimension of } \\
\text { Sustainability }\end{array}$} & \multicolumn{3}{|c|}{ Critical barriers of sustainability (in top down order) } \\
\hline & 1st & 2nd & 3rd \\
\hline Social & $\begin{array}{l}\text { Community } \\
\text { Participation of } \\
\text { members } \\
\end{array}$ & $\begin{array}{l}\text { Training of local } \\
\text { Communities and } \\
\text { administrator }\end{array}$ & $\begin{array}{l}\text { CBO organization } \\
\text { procedures }\end{array}$ \\
\hline Institutional & $\begin{array}{l}\text { local government } \\
\text { dedication, support and } \\
\text { leadership }\end{array}$ & $\begin{array}{l}\text { Leadership } \\
\text { Coordination and } \\
\text { Supervision }\end{array}$ & $\begin{array}{l}\text { Enforcement of local } \\
\text { by-laws }\end{array}$ \\
\hline Technical & $\begin{array}{l}\text { Soil and Water } \\
\text { Conservation }\end{array}$ & Conservation tillage & $\begin{array}{l}\text { Communal Pasture } \\
\text { management }\end{array}$ \\
\hline Financial & Financial management & $\begin{array}{l}\text { Diversified Income } \\
\text { sources }\end{array}$ & Marketing \\
\hline Environmental & $\begin{array}{l}\text { Establishing local-level } \\
\text { environmental action } \\
\text { plan }\end{array}$ & $\begin{array}{l}\text { Information } \\
\text { communication and } \\
\text { advocacy }\end{array}$ & $\begin{array}{l}\text { Formulation and } \\
\text { enforcement of bylaws } \\
\text { for closed areas }\end{array}$ \\
\hline
\end{tabular}

\section{Social sustainability:}

Repeatedly occurring critical barriers that affect social sustainability across the studied CBOs that deserve areas for improvement in the future are community participation, training of local community members and administrators and information management. A participation index analysis of farmers' participation level in all watershed management activities verified that the vast majority of the farmers (96.4\%) have participated in fewer than $60 \%$ of intended activities. Furthermore, over half of the farmers were found to participate in fewer than $40 \%$ percent of intended activities. Looking at participation in project stages, it was found that $51 \%, 43 \%$ and $1 \%$ of respondents participated in planning, implementation, and monitoring and evaluation (M\&E) phases of the intervention, respectively.

The training and discussions held both at Zonal and Wereda levels were not inclusive and community focused due to financial and time shortages. Trained individuals are more likely to be sustained than those without. Those trained can continue to provide benefits, train others and form a constituency in support of the program [15]. As a result, at the beginning of the project implementation period, community members were suspicious of the development work. Some members had fear of losing their land to investors, etc. The support of local authorities and sector offices with the training was essential when carrying out an analysis and devising solutions with some community members who misunderstood the objective of the initiative. In the process of establishing sustainable CBOs, the roles, concerns, and views of these people should not be overlooked, regardless of any preconceptions regarding the position they adopt. 


\section{Institutional Sustainability:}

Even though the CBOs are established as an autonomous and self-support and administered legal entities local government dedication, support and leadership are critical for the sustainability of CBOs in the context of rural Ethiopia. The role played by zonal agricultural office in supporting the community technically and monitoring activities on the ground has been satisfactory. However, some members were not fully committed and did not understand the whole philosophy of community-based development. Things were taken simply as "business as usual".

These initiatives were brought to reinforce regular activities of the respective Woredas. This was taken positively and as a plus in an effort of the CBO to achieve the intended goals. Moreover, as the overall natural resource management activities in the woreda is coordinated and implemented by the woreda administration, these CBOs were supported with material and technical support from the local administration and the natural resource team. Institutional instability in the zone and woredas has been a challenge during the years of CBOs project operation. The Cooperative Development and Promotion Office in the Zone and woredas have been weak to provide the necessary support.

Although the presence of locally evolved and well-articulated by-law for natural resource management is a plus and a key step for success, enforcing it was quite a challenge due to various socio-economic factors. In all the CBOs lack of enforceability and proper implementation was found to be a major problem for their sustainability. There are no tangible disincentive mechanisms in place for negative activities on the natural resources. The presence of well-articulated sanctioning mechanism in the by-law and its effective implementation is one of the facilitating conditions for effective governance in natural resource management [16]. While $88 \%$ of the community members have confirmed the presence of locally developed and agreed by-law, about $40 \%$ of them claimed as the by-law was not binding and effectively functional. $11.2 \%$ of respondents are not familiar with the local bylaw. Only $14.7 \%$ of the respondents regarded the by-law as binding and functional. This was found contradictory with the basic principles of CBOs. Due to this, even though all members of the $\mathrm{CBO}$ are supposed to equally participate and contribute in the different watershed activities, the majority of the respondents (60\%) confirmed the dominance of free riders in all activities.

\section{Technical Sustainability}

The area is dominantly hilly and mountainous highlands that are found on the backslope of Choke Mountain. The soil type is predominantly, shallow with rapid drainage characteristics (Liptosols) and altitude varies between 2800 and $3800 \mathrm{~m}$. To reduce the extent of soil erosion at the watershed level, construction of bund and hillside terraces were planned following a participatory watershed planning tool. The local development agents (DAs) are supposed to instruct layout and implementation of the bunds and hillside terraces as per the 
technical manual. However, their primary target is meeting the target / cover large area in short time possible. Farmers are supposed to construct and complete the structures and found to influence the layout. The reason, from the questionnaires and focus group discussion, is that these structures take more land and is not convenient for traditional plowing. They prefer small and widely spaced bunds which is not technically sustainable for the area. SWC activities such as hillside terrace construction have been largely weak due to limited farmers' experience and difficult terrain. The planned live fencing of individual plots, establishing hedgerows along the contours of sloppy farmlands and cultivation of various crops in the alleys as part of integrated agricultural land management was not found showing as such successful accomplishment.

Adoption of soil conservation structures (SCS) has been low in high rainfall areas of Ethiopia mainly due to crop yield reduction, increased soil erosion following breaching of SCS, incompatibility with the tradition of cross-plowing and water-logging behind SCS. A new type of conservation tillage (CT) involving contour plowing and the construction of invisible subsoil barriers using a modified Maresha winged 'subsoiler' is suggested as a means to tackle these problems as an integral part of the SCS. We investigated the effect hypothesized that integrating the new CT with SCS will have a positive effect on the surface runoff, water-logging, soil loss, crop yield and plowing convenience. Farmers found CT convenient to apply between SCS. Surface runoff appeared to be reduced under CT by 48 and $15 \%$, for wheat and tef, respectively. As a result, CT reduced sediment yield by 51 and $9.5 \%$, for wheat and tef, respectively. Significantly reduced water-logging was observed behind SCS in CT compared to TT. Grain yield of wheat and tef has increased by 35 and $10 \%$ respectively as compared with the traditional plowing [17]. However, CT technology has not been introduced successfully due to lack of local private sector that can reproduce the modified Maresha "winged subsoiler".

Each CBO under SGP in the woreda has demarcated and enclosed previously degraded area as area closure, particularly the sensitive afroalpine ecosystem that is found on the mountain summit. At the back-shoulder of the mountain (lower altitude) long disappearing tree species has been remerging include Podocarpus, Wanza, Hygenia abyssinica, and Juniperus procera, etc. However, this has not gone enough due to free grazing and firewood shortages and presence of a huge no of landless individuals in the area.

\subsection{Financial Sustainability}

Even though the community initially accepted the involvement of the Agriculture office in managing the finance, the $\mathrm{CBO}$ leaders cannot mobilize financial resources without the approval of woreda agricultural office natural resource management and cooperative teams. CBO leaders as delegates of the general assembly and woreda agriculture office jointly manage the fund. The majority believes that this arrangement has created a sense of responsibility and accountability for both parties and sense of trust for the community at 
large. Project time is obviously short to achieve the intended objectives such as revival of biodiversity resources/ecosystem resources on and around the sensitive Choke Mountain eco region and enhancing community livelihoods. However, as this is the general norm for SGP grant system, necessary adjustment has been done to achieve, though partially, most of the objectives within the given timeframe.

The sustainability issues that are pertinent for financial sustainability are the following:

- Limited capacity and experience: Budgetary transfer is effectively facilitated by the Zonal Coordinator with the help of Woreda Cooperative Promotion Office;

- Effective project budget utilization by the CBOs has been a challenge; timely use fund and timely implementation of planned activities have been constraints;

- The extended bureaucracy and the time it takes to purchase goods is too long in view of the critical timing of natural resources management and other farming activities; and

- Budgetary constraints of Government run offices that impacted negatively the level of support given to CBOs.

\subsection{Environmental Sustainability}

An environmentally sustainable system must maintain a stable resource base (land cover, land management, land use system, water availability, and population density), avoid over-exploitation of renewable resources, and preserve biodiversity. This requires ample time and reaching out to the various interests of all the community members and other stakeholders. Despite the presence of Local-level Environmental Management Action Plan Development (LEAD) manual with a guideline and detail steps on how to organize CBOs things were done in a rush to meet the donor's deadline without a community-wide and genuine participation $[18,19]$. As a result, not all community members accept and own the outcomes of the project in ways that are sustainable.

Information communication and advocacy regarding environmental issues in view of the magnitude of the land degradation and CC related problems in the Choke Mountain watersheds and its devastating consequences is far below the expected. This necessitates the local leaders and environmental experts to strengthen the tradition of public meetings, public debates, and public lectures to a range of target groups, also including policy and decision makers. Lobbying and advocacy, particularly on environmental issues, is largely very poor in the country compared to the magnitude of the degradation of natural resources.

There have been many sporadic initiatives that have positively contributed to environment and development in the country both at the individual and institutional levels. However, there has been limited tradition of encouraging such noble initiatives through incentive schemes. There are no tangible disincentive mechanisms in place for negative activities on the natural resources. Despite the fact that there are policy and legislative 
frameworks to protect the natural resources, there is no clear and applicable articles in the laws in holding an offender or polluter pay for and correct or restore damages that inflicted upon the physical environment.

\section{Conclusions}

Climate adaptation is a social learning process that creates the capacity to cope with CC-related impacts. Knowledge gaps remain as to how long these practices would be able to counteract the impacts of $\mathrm{CC}$, and how best to design and promote adaptation processes, in view of uncertainty in climate change scenarios and location-specific impacts. However, immediate action is needed to manage the existing and future risks within the framework of broader understanding on the most likely impacts of climate change. Case studies of adaptation processes are needed that will add to gathering, disseminating and replicating good practices, especially for the most vulnerable. Since we are not yet able to anticipate exact future impacts of $\mathrm{CC}$, particularly at local scale, the project suggests that program on climate change adaptation should have an intermediate goal of empowering communities to adapt to the impacts in a broader ecosystem perspective. In pursuing this goal, climate adaptation should focus on support for the decision-making and capacity-building processes that shape social learning, technology transfers, innovations, and development pathways.

The concept of community and ecosystem-based adaptation in rural areas of Ethiopia encompasses a wide range of strategies at local and landscape scales, enabling communities to address $\mathrm{CC}$ in an effective way. As described above, 21 targeted CBA development projects have been implemented in Choke Mountain watersheds over the last 5 years. The approach has centered on individual households within target micro-watersheds, with a focus on empowering vulnerable people with the knowledge, skills and resources they need to take action on the CC adaptation strategies appropriate for their lives and livelihoods. In all projects, preservation of the natural resource base was taken as an entry point for planning adaptive actions. The projects are rooted in a participatory, comprehensive analysis of the biophysical vulnerability that allows different groups-such as poor women or other marginalized people in the community - to identify targeted strategies based on their specific needs and priorities. While much has been learned through these projects, the sustainability of projects that take the natural resource base as an entry point has come into question. Interventions that are effective during the active project period, when external investments in adaptation capacity are made available, often fail to establish the link to markets that is required to sustain efforts after the project ends.

The sustainability of Individual CBOs are assessed on aggregate rating of the five sustainability dimensions (social, institutional, technical, and financial and environment) and rated as $0.1,0.2,0.5,0.1$ and 0.1 , respectively according to their contribution in achieving the aims of the CBOs. The aggregate value of sustainability ranges from 0.39 to 0.66 with a median of 0.4680 , which is below the average value. There was no sustained CBO that 
obtained a $70 \%$ score (or more) in all sustainability dimensions and aggregated form. Six CBOs (30\%) sustained but at risk CBO getting a 50\% score (or more) in an aggregated form from all dimensions. The rest $70 \%$ (14 CBOs) fail to obtain a 50\% score in an aggregated form or in any of the factors and are not sustainable in all the dimensions.

Repeatedly occurring critical barriers that affect social sustainability across the studied CBOs that deserve areas for improvement in the future are community participation, training of local community members and administrators and information management. Even though the $\mathrm{CBO}$ are established as an autonomous and self-support and administered legal entities, local government dedication, support and leadership are critical for the sustainability of CBOs in the context of rural Ethiopia. The critical barriers across the studied CBOs performance that are areas for improvement in the future are Soil and Water Conservation, Conservation tillage and Communal Pasture management due to the due to lack of famers' experience and difficult terrain. The planned live fencing of individual plots, establishing hedgerows along the contours of sloppy farmlands and cultivation of various crops in the alleys as part of integrated agricultural land management was not found showing as such successful accomplishment. Conservation Tillage technology has not been introduced successfully due to lack of local private sector that can reproduce the modified Maresha "winged subsoiler". The financial sustainability dimension are constrained by limited capacity and experience and extended bureaucracy. Lobbying and advocacy, particularly on environmental issues, is mostly very poor in the country compared to the magnitude of the degradation of natural resources.

However, there are visible indications of the impact of the project towards environmental sustainability. The re-emergence of long disappeared/ disappearing crop and tree species (varieties) and the wide use of compost are worth mentioning. A number of disappearing barley and potato farmer varieties have been since re-emerging through collecting and widely multiplying the seeds. Disappearing indigenous tree species such as Hygienia abyssinica, Juniperus procera Erica spp (Asta) and Hypericum revolutum (Amijja) were regenerated through strict communal area closure measures. Compost is prepared continuously throughout the year by almost all community members thus used both on field crops as well as on backyard gardens. Farmers in these CBOs don't rely on commercial fertilizer to enhance soil fertility.

Based on this experience, markets could be considered as entry that is more appropriate and exit point for future resilience building efforts. This recognition has yielded a model that centers on the establishment and implementation of community-based innovation platforms, devoted to achieving a GRGE through dissemination and uptake of proven technologies and practices [1, 10]. As learned at Choke Mountain, an effective partnership is a necessary precondition to market-based technology transfer. The IP model also acknowledges that it is necessary to establish an enabling policy environment to make the partnership arrangement work legally. 
Experience at Choke Mountain has provided a strong foundation for this effort, but it will be critical to maintain active analysis and a flexible approach to implementation as the Community-base Innovation Platforms (CIPs) experiment moves forward. The major activities of these IPs focus on transforming the agriculture sector based on agroecosystem and vulnerability assessment through:

- establishing voluntary local institutions (CIPs);

- accelerating access to technology and investment;

- improving market mechanisms for climate resilient and sustainable products and practices;

- defining environmental management as a community-level issue; and

- empowering community members to address governance matters at the local level, and empowering communities to identify broader governance needs.

\subsection{Recommendations}

The key lessons drawn from the project implemented jointly by AAU, EPA, GEF-SGP and ESAT to promote livelihood adaptation to $\mathrm{CC}$ in Choke Mountain ecosystems of the upper Blue Nile are the following:

- Empowering Community Based Organizations (CBOs): Empowerment of community members through skill training was highly accepted by all stakeholders and contributed to the sustainability of CBOs. Woreda as well as zonal technical taskforce members have imparted important skill trainings like SWC, bee keeping, production and use of fuel saving stoves, and on organizational and financial management topics to $\mathrm{CBOs}$ which helped them achieve the a results explained below. Experience sharing activities among CBOs to exchange lessons and share best practices was also very successful. As a result, community members who were suspicious of the development work at the beginning because of their fear of losing their land to investors have become active participants of the CBOs, through repeated consultation and involvement of woreda steering and technical committees. As a result membership has been steadily growing since establishment as people come to realize the benefit of organizing in association/cooperative to get better benefit collectively rather than individually.

- Multiple and integrated adaptation measures across sectors are essential. Project findings confirm that climatic conditions and anthropogenic factors mutually reinforce chronic vulnerability to climate variability and natural disasters. Technology, on its own, is at best a partial solution to CC. Therefore, technological solutions should be embedded in relevant social and environmental contexts. The 
project confirms the need for multiple but integrated pathways across sectors to improve adaptive responses of local communities, especially the poorest sectors of the community. Neither an agricultural nor any other intervention alone can provide sufficient scope to manage the future CC risks. Short-term and long-term adaptive measures in agriculture, linked with clear focus on future risks, and must be integrated into cross-sectoral planning.

- Ensuring community participation should be introduced early in the project design phase. Sustainability of CBOs is about community development, which is built on the capacities and skills of community members to manage representative and fair structures that can respond to both immediate and long-term prevention of risks and meeting needs, and developing solutions while upholding individual rights. Maximum ownership and sustainability are achieved when interventions are responding to the community-driven demands. Alleviating poverty and ensuring household-level food security under changing climate conditions is a major challenge. Ensuring community participation in CC adaptation as well as top-down institutional development and policy support is crucial for managing future risks at community level in general and for the agriculture sector in particular. Without broad participation, only a few will decide for all, and those few might control information and resources. This can lead to abuse of power. Meaningful participation by all will often require special efforts to ensure that those traditionally marginalized, such as women, children, older persons, persons with disabilities and minority groups, are given support and specific opportunities to contribute. It might also be necessary to work with traditional leaders to encourage their active support. This is essential for avoiding token participation and failure, which reinforces marginalization and discrimination.

- Building the capacity of local governments: Local sustainability means that an area is designed and operates in a way that uses energy and natural resources efficiently and equitably, for both present and future generations of humans and other species. Sustainable communities meet their current needs without compromising the environment and depletion of the natural resource base for future generations. Farming communities make routine decisions affecting the sustainability of both their community and the environment. Making a community sustainable means integrating economic development, community development, and environmental protection. This cannot be achieved without the direct involvement of local government. Building sustainable communities requires a proactive, localized, and highly participatory approach that depends upon the unique role and capabilities of local government. Even though there is a positive change in recent years, the capacity of weredas and kebeles is still far from what is expected to bring sustainable development. Awareness raising and capacity-building processes are urgently needed at all levels that will support long-term learning processes and, at the same time, take the broad range of eco-systems and socio-economic conditions into consideration. A more systematic 
and consistent application of already known sustainable agricultural, forestry and fisheries may serve as suitable entry point to adapt to and mitigate the impacts of CC and environmental conditions.

- Adaptation to CC is a location-specific issue. Decentralized ways of working are needed within the framework of coherent national policies. There cannot be one-sizefits-all solutions at local level. Managing anticipated risks requires developing location-specific adaptation options that consider biophysical, socio-economic, and socio-cultural factors. The project experience argues in favor of establishing more and better participatory and practical learning and action research and development platforms to develop and replicate innovative adaptive technologies jointly with farmers. Land-use planning, watershed management, plant production, farming systems research, development of drought-tolerant varieties and small-scale water harvesting practices are already in place.

- Factoring existing knowledge about climate risks into new approaches in the context of $\mathrm{CC}$ adaptation is a good entry point. Adaptation practices involving community actions such as modern bee keeping, highland fruit and fuel saving technologies were highly preferred, as the practice provided substantial income throughout the year. Without net financial benefits for farmers, there seems to be little scope for local adaptation of any new technology at this stage

- Applying a livelihoods perspective is helpful to understand and promote local-level adaptation to CC. Community and institutions, organizations, policies, and legislations influence household assets. The institutions and processes operating in both public and private spheres and from household to national levels determine access to assets, livelihood strategies and vulnerability to CC. Adding CC adaptation through a livelihood perspective improves the adaptive capacity of farmers by increasing household access to assets and services.

\section{Acknowledgements}

Work on this paper was supported in part by Addis Ababa University Thematic Research programme, UNDP-Small Grants Programme, and by NSF-CNH GEO-1211235.

\section{References}

1. Simane, B., Zaitchik, B.F and Desalegn Mesfin. Building climate change resilience in the Blue Nile / Abay Highlands. A framework for action. International Journal of Environmental Research and Public Health. 2012, 9, 610-631.

2. Simane, B., Zaitchik, B.F and and Ozdogan,M. Agroecosystem Analysis of the Choke Mountain Watersheds, Ethiopia. Sustainability 2013, 5, 592-616. 
3. Federal Democratic Republic of Ethiopia (). Ethiopia's Climate-Resilient Green Economy. Green economy strategy. 2011, Addis Ababa, Ethiopia. Pp

4. Ministry of Finance and Economic Development (MoFED).. Ethiopia's Growth and Transformation Plan (GTP), 2011/12-2014/15. 2010. Addis Ababa, Ethiopia Pp 85.

5. Andrade Pérez, A., Herrera Fernandez, B. and Cazzolla Gatti, R. (eds.). Building Resilience to Climate Change: Ecosystem-based adaptation and lessons from the field. Gland, Switzerland: IUCN. 2010. Pp 164.

6. Dipankar Datta. Sustainability of community-based organizations of the rural poor: Learning from Concern's rural development projects, Bangladesh. Oxford University Press and Community Development Journal. 2005

7. Abdullah, T. And Ali, A.K.M.M. Stock Taking of Good Practices of the Organizations Promoting Sustainable CBO ,Enfants dumonde, Dhaka, Bangladesh. 1998

8. Danida,. Community-based natural resource management. Technical Advisory services, Ministry of Foreign Affairs of Denmark. 2007. http://www.ifad.org/pub/other/cbnrm.pdf.

9. Rotha, K.S. Understanding key CBNRM concepts, The Development of Community Based Natural Resource Management (CBNRM) in Cambodia. 2005

10. Simane, B. Building resilience to climate change and green economy in mountain ecosystems of ethiopia. Integrating research, capacity building and sustainable development activities. In Proceedings of the Stakeholders Workshop, Debre Markos, Ethiopia, 10-13 June 2011.

11. Lakew Desta, Carucci, V., Asrat Wendem-Ageňehu and Yitayew Abebe (eds.).. Community Based Participatory Watershed Development: A Guideline. Parts 1 and 2. Ministry of Agriculture and Rural Development, Addis Ababa, Ethiopia. 2005. 176 and 114 pp.

12. Zaitchik, B.F.; Simane, B.; Habib, S.; Anderson, M.C.; Ozdogan, M.; Foltz, J.D. Building climate resilience in the blue nile/abay highlands: A role for earth system sciences. Int. J. Environ. Res. Publ. Health 2012, 9, 435-461.

13. Saaty, T.L. (1995), Decision Making for Leaders: the Analytic Hierarchy Process for Decisions in a Complex World, RWS Publications, Pittsburgh.

14. Wolfslehner B., Vacik H. and Lexer M. J.. Application of the analytic network process in multi-criteria analysis of sustainable forest management. Forest Ecology and Management, Volume 207, Issue 1-2, 7 March 2005, Pages 157-170. http://dx.doi.org/10.1016/j.foreco.2004.10.025

15. FAO. Community Based Adaptation in Action. FAO Environment and Natural Resources Service Series, No. 14 - FAO, Rome. 2008. Pp 64. ISBN 978-92-5-106056-8

16. Osrtom E. Goverening the commons: The Evolution of Institutions for collective actions, Cambidge, England, Campridge university press. 1990

17. Temesgen, M.; Uhlenbrook, S.; Simane, B.; van der Zaag, P.; Mohamed, Y.; Wenninger, J.; Savenije, H.H.G. Impacts of conservation tillage on the hydrological and 
agronomic performance of fanya juus in the upper blue nile (abbay) river basin. Hydrol. Earth Syst. Sci. 2012, 16, 4725-4735.

18. Simane, B. Local-Level Environmental Action Plan for Development (LEAD); Institute of Development Research, Addis Ababa University: Addis Ababa, Ethiopia, 2008.

19. Azmeraw Ayehu. Nature and Determinants of Participation in Community based Participatory Watershed Management in Choke Mountain: The Case of Chemoga Watershed, East Gojjam, Ethiopia; Addis Ababa University: Addis Ababa, Ethiopia, 2010

(C) 2013 by the authors; licensee MDPI, Basel, Switzerland. This article is an open access article distributed under the terms and conditions of the Creative Commons Attribution license (http://creativecommons.org/licenses/by/3.0/). 
Annex 1. Descriptive Statistics of the variable used in assessing Sustainability of Community based Organizations

\begin{tabular}{|c|c|c|c|c|c|}
\hline Dimensions & Indicators/factors & Minimum & Maximum & Mean & Std. Deviation \\
\hline \multirow{4}{*}{$\begin{array}{l}\text { Social } \\
\text { sustainability } \\
(0.1)\end{array}$} & $\begin{array}{l}\text { Training of local Communities and } \\
\text { administrator }\end{array}$ & 35 & 95 & 64.45 & 18.400 \\
\hline & $\begin{array}{l}\text { Information and Knowledge } \\
\text { management }\end{array}$ & 30 & 70 & 42.50 & 14.002 \\
\hline & Establishing school environmental club & 10 & 70 & 55.75 & 17.341 \\
\hline & $\begin{array}{l}\text { Developing Local Level Environmental } \\
\text { Action Plans }\end{array}$ & 15 & 85 & 41.40 & 21.693 \\
\hline \multirow{3}{*}{$\begin{array}{l}\text { Institutional } \\
\text { sustainability } \\
(0.2)\end{array}$} & Training for of the Planning team & 35 & 95 & 63.70 & 14.187 \\
\hline & Supervision & 25 & 65 & 33.05 & 12.020 \\
\hline & Annual Workshop & 35 & 62 & 45.40 & 12.601 \\
\hline \multirow{8}{*}{$\begin{array}{l}\text { Technical } \\
\text { sustainability } \\
(0.5)\end{array}$} & Improved SWC Practices & 30 & 86 & 61.90 & 19.676 \\
\hline & Conservation of farmers' varieties & 35 & 100 & 72.10 & 17.066 \\
\hline & Composting & 80 & 108 & 93.25 & 9.244 \\
\hline & Conservation tillage & 10 & 40 & 19.75 & 12.511 \\
\hline & Production of Mirt Stove & 25 & 90 & 52.50 & 18.291 \\
\hline & Communal Pasture management & 20 & 61 & 33.60 & 11.014 \\
\hline & Bee keeping & 10 & 70 & 39.10 & 17.544 \\
\hline & Forest Establishments & 35 & 100 & 62.30 & 15.335 \\
\hline \begin{tabular}{|l} 
Financial \\
sustainability \\
$(0.1)$ \\
\end{tabular} & Audit & 10 & 100 & 53.65 & 33.547 \\
\hline \multirow{6}{*}{$\begin{array}{l}\text { Environmental } \\
\text { sustainability } \\
(0.1)\end{array}$} & Formulation of bylaws & 20 & 95 & 47.50 & 23.200 \\
\hline & Delineation of area Closure & 35 & 100 & 67.85 & 13.854 \\
\hline & Establishment of management plan & 15 & 63 & 36.85 & 15.020 \\
\hline & Introduce enrich biodiversity & 35 & 75 & 61.80 & 14.348 \\
\hline & Spring development & 10 & 100 & 36.15 & 37.376 \\
\hline & Construction of water trough & 10 & 95 & 32.00 & 32.622 \\
\hline
\end{tabular}

